\title{
Shape Correction Factor for Drying Shrinkage in a Concrete Cross-Section
}

\author{
N. Reybrouck ${ }^{1}$; P. Criel $^{1}$; R. Caspeele ${ }^{1}$; and L. Taerwe ${ }^{1}$ \\ ${ }^{1}$ Magnel Laboratory for Concrete Research, Department of Structural Engineering, \\ Ghent University, Technologiepark-Zwijnaarde 904, Ghent. E-mail: \\ Nicky.Reybrouck@UGent.be
}

\begin{abstract}
A concrete member is subjected to loads for a long period of time, during which creep and shrinkage of concrete develop gradually. The prediction of this timedependent behaviour is important as it may cause serious serviceability problems in concrete structures. A time-dependent analysis is commonly based on empirical equations according to design codes where the function describing the time dependent increment of shrinkage and creep is commonly, among others, defined based on the notional size of the element. In case of imbedded steel or insulated boundaries the moisture transport can be partially affected or prevented. Also, the geometry and size of the cross-section have an important effect on the shrinkage behaviour of a concrete member. Hence, the performance of commonly used empirical formulas may be improved by applying a correction factor on the notional size. In order to investigate the impact of these various factors on the net macroscopic shrinkage used in analysis and design, a discretized 2D physical model was developed. The model was used to simulate drying of a concrete cross-section by determining the moisture distribution in the cross-section as function of time.
\end{abstract}

\section{INTRODUCTION}

Creep and shrinkage of concrete result in long-term deformations that may cause serviceability problems and it is therefore important to predict this effect properly. The mechanisms causing creep and shrinkage of concrete show significant correlation with the moisture distribution of the concrete cross-section. This study is focussing on the determination of the influence of the geometry of a concrete member on the drying shrinkage response.

The effect of moisture transportation has shown considerable effect on shortening of concrete members in case of imbedded steel profiles (Seol 2008). The differential moisture distribution should therefore be taken into account in order to enhance the accuracy of the prediction of strain development. The deformation of concrete members depends highly on the possible moisture transport routes affected by for example a different shape geometry (T-beams), hollow areas (hollow core elements), obstructions (imbedded steel) and boundary conditions (isolations and exposed surfaces). 
The moisture diffusion and differential drying shrinkage was determined using finite element analysis. This behaviour is determined by analysing the progress of moisture at each point of the concrete section in time.

\section{NUMERICAL ANALYSIS OF DRYING CREEP AND SHRINKAGE}

The creep and shrinkage behaviour is modelled using a finite element method combined with Fick's second law of diffusion, which describes the transient phenomena within the concrete section during each time-step of the analysis. The drying of a concrete cross-section with time is given by (Sue-Tae 2011):

$$
\frac{\partial H}{\partial T}=\nabla \cdot\left(D_{S}(H, T) \nabla \mathrm{H}\right)
$$

where $H$ is the relative pore humidity and $t$ is time. The progress of moisture diffusion through these specimens was calculated using the non-linear moisture diffusion equation (Bazant 1972). For isothermal conditions the non-linear diffusion coefficient $D$ can be expressed as a function of the relative pore humidity $H$ as defined in Model Code 2010 (Fib 2010) as:

$$
D(H)=D_{1}\left(\alpha+\frac{1-\alpha}{1+\left(\frac{1-H}{1-H_{c}}\right)^{n}}\right)
$$

where $D_{1}$ is the maximum of $D(H) ; D_{0}$ is the minimum of $D(H) ; \alpha=D_{0} / D_{1}$ (assumed 0.05); $H_{C}=$ the relative pore humidity at $D(H)=0.5 D_{1}$ (assumed 0.80 ) and $n$ is an exponent (assumed 15). The free shrinkage at each point of the section is determined based on local drying and calculated as suggested by (Kim 2012; Bazant 1994):

$$
\Delta \varepsilon_{s h}\left(t_{i}, t_{i-1}\right)=\varepsilon_{s}^{0} g_{s}\left(t_{i}\right)\left(1-h\left(t_{i}, x, y\right)^{3}\right)-\varepsilon_{s}^{0} g_{s}\left(t_{i-1}\right)\left(1-h\left(t_{i-1}, x, y\right)^{3}\right)
$$

where $\Delta \varepsilon_{s h}\left(t_{i}, t_{i-1}\right)$ is the shrinkage strain during time period $\left(t_{i}, t_{i-1}\right) ; \varepsilon_{s}^{0}$ is the magnitude of the final shrinkage; $g_{s}\left(t_{i}\right)=E_{c}\left(t_{0}\right) / E_{c}\left(t_{i}\right) ; E_{c}(t)$ is the Young modulus at time $t$ and $h(t, x, y)$ is the local moisture content at time $t$.

The moisture distribution at each time step and each material point within the concrete section is determined using the initial strains and induce non-uniform restraining stresses. An example of the moisture distribution of a T-shaped crosssection is shown in Figure 1. This analysis of shrinkage and creep strains was performed by using a numerical step-by-step procedure in time in combination with transformed section properties adjusted in time. 

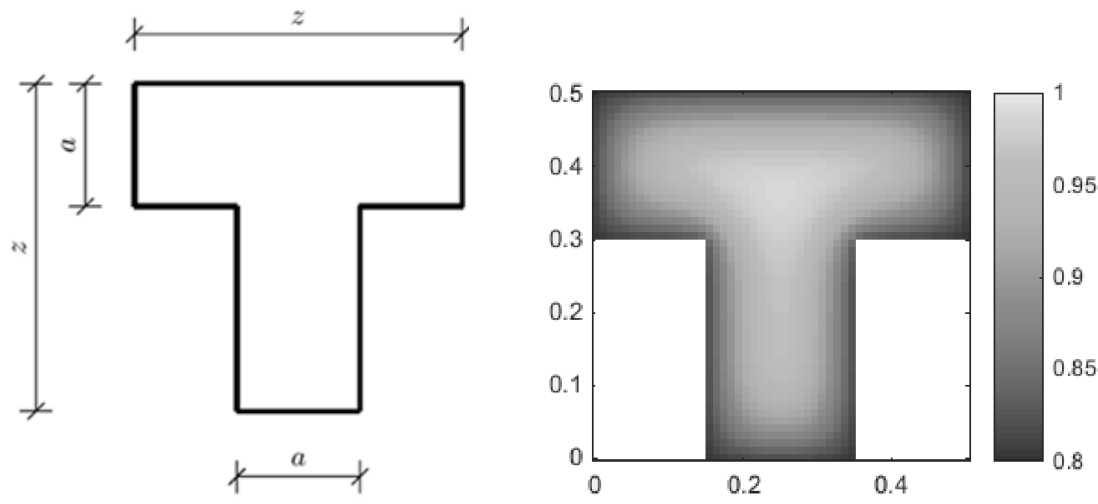

Figure 1. Geometry of the studied $T$ cross-section and moisture content example.

The local shrinkage behaviour in a specific point of the cross-section is determined based on the local moisture content history. This local strain response throughout the structural element in space/time is then transformed to a section-wide temporal shrinkage response by applying the principle of Navier-Bernoulli. The fictitious force $\Delta N$ and bending moment $\Delta M_{x}$ corresponding to restrain the local free shrinkage increment $\Delta \varepsilon_{s h}\left(x, y, t_{i}, t_{i-1}\right)$ at time interval $\left(t_{i}, t_{i-1}\right)$ is determined by (Ghali 2011):

$$
\begin{aligned}
\Delta N & =\int_{A} E_{c}(t) \Delta \varepsilon_{s h}\left(x, y, t_{i}, t_{i-1}\right) d A \\
\Delta M_{x} & =\int_{A} E_{c}(t) \Delta \varepsilon_{s h}\left(x, y, t_{i}, t_{i-1}\right) y d A
\end{aligned}
$$

in which $y$ is the $y$-coordinate of the observed material point and $A$ is the area of the cross-section. The strain increment $\Delta \varepsilon_{\text {sh }}\left(t_{i}, t_{i-1}\right)$ and curvature increment $\Delta \kappa_{\mathrm{sh}}\left(t_{i}, t_{i-1}\right)$ are then calculated by:

$$
\left\{\begin{array}{l}
\Delta \varepsilon_{\mathrm{sh}}\left(t_{i}, t_{i-1}\right) \\
\Delta \kappa_{\mathrm{sh}}\left(t_{i}, t_{i-1}\right)
\end{array}\right\}=\frac{1}{E_{c}(t)}\left[\begin{array}{ll}
E A & E S \\
E S & E I
\end{array}\right]^{-1}\left\{\begin{array}{c}
-\Delta N \\
-\Delta M_{x}
\end{array}\right\}
$$

in which $E A, E S$ and $E I$ are respectively the area, the first moment of area and the second moment of area of the transformed cross-section multiplied with the modulus of elasticity $E_{c}(t)$. The final shrinkage $\varepsilon_{s h}(t)$ is given by:

$$
\varepsilon_{s h}(t)=\sum_{i=1}^{n} \Delta \varepsilon_{s h}\left(t_{i}, t_{i-1}\right)
$$

\section{RESULTS OF THE NUMERICAL SIMULATION}

The size of each element used in the numerical analysis was chosen equal to 5 $\mathrm{mm}$ and the simulation was performed for a period of 10 years using time step increments of 5 hours. An example of the drying shrinkage development obtained by the numerical analysis for different geometries such as rectangular, circular and Tshaped cross-sections are given in Figure 2. 


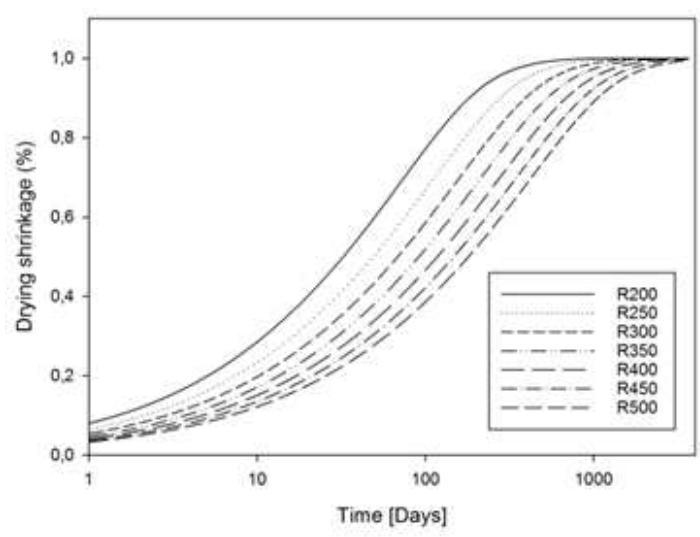

(a)

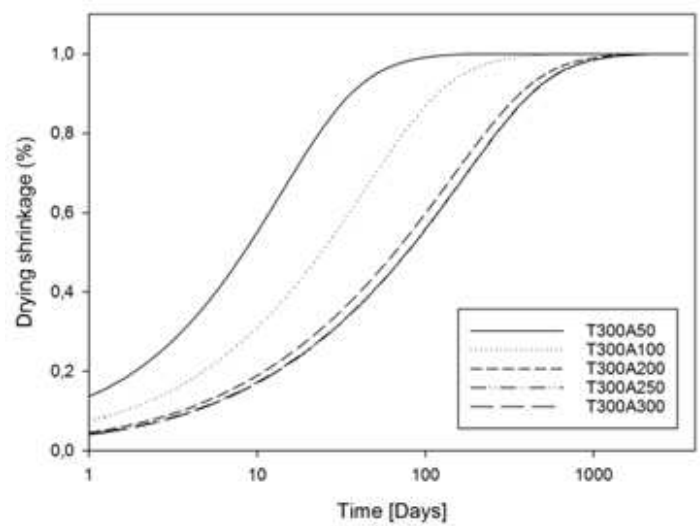

(c)

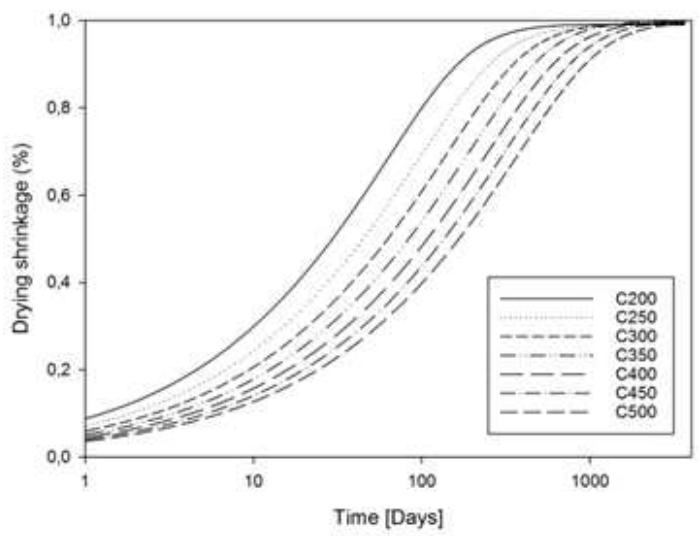

(b)

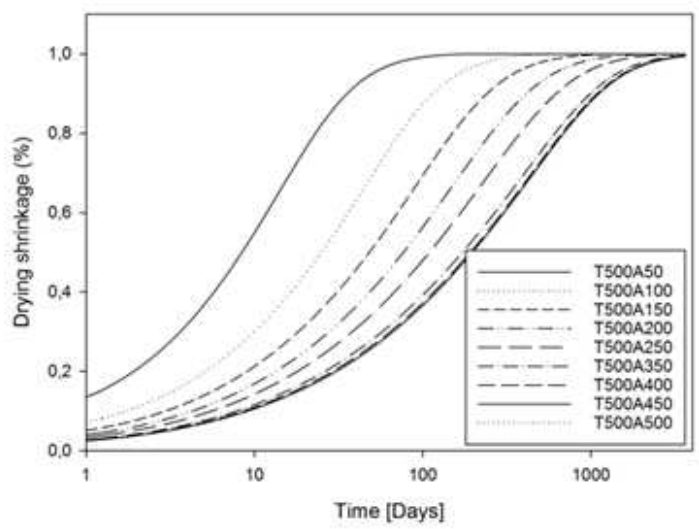

(d)

Figure 2. Drying shrinkage development for different cross-sections (a) Rectangular (b) Circular (c) T-beam with $\mathrm{z}=300 \mathrm{~mm}$, variable flange thickness a (d) T-beam with $\mathrm{z}=500 \mathrm{~mm}$, variable flange thickness $a$.

\section{REMARK}

Drying shrinkage results in a shortening of the concrete element. Crosssections who do not have two axis of symmetry will also produce a curvature (inclined plane) due to the non-uniform shrinkage (see Figure 3). The curvatures as function of time obtained from the numerical analysis of a T-beam with a width of $500 \mathrm{~mm}$ are shown in Figure 4.

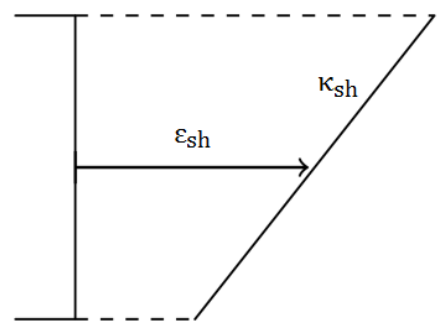

Figure 3. Curvature due to the non-uniform development of shrinkage. 


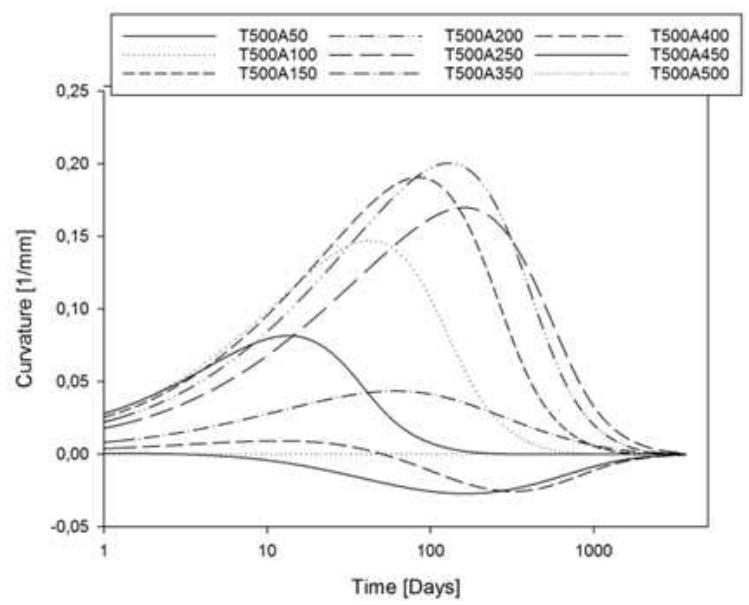

Figure 4. Curvature due to the development of shrinkage in case of T-beams. (example $\mathrm{z}=500 \mathrm{~mm}$ )

\section{SHAPE CORRECTION FACTOR}

An averaged cross-sectional approach in which the behaviour of the structural member is equal for the whole cross-section is a simple, fast and efficient method for the analysis of creep and shrinkage in concrete structures and is widely used in engineering practice. The formulations given in Model Codes and guidelines such as CEB-FIP (fib 2010), ACI (ACI 1998), B3 (Bazant 1995), B4 (RILEM 2015) are generally used to calculate the shortening of concrete members. These methods provide fairly good results as an average for plain concrete cross-sections. It considers mix properties, size and exposed ambient conditions. The progress of drying shrinkage in Eurocode 2 is expressed as a function of the notional size of the element. Non-uniform behaviour of the cross-section cannot be captured correctly using these methods but can be accounted for using correcting parameters. The shrinkage and creep equations found in Eurocode have been modified to predict the shortening of the concrete element more accurately for different shapes. In this paper a modified shrinkage model is suggested to a determine shape correction factor $\alpha_{T}$ to improve the accuracy of the formulations for drying creep of concrete by modifying the notional size $h_{0}$ in Eurocode 2. It is assumed that the differences between the different shapes are caused only by the moisture diffusion process. Consequently, the proposed method was used to perform a numerical analysis on a wide range of different shapes and dimensions for T-shaped beams to improve the local drying shrinkage prediction. The function $\beta_{d s}\left(t, t_{s}\right)$ (EN 1992-1-1) describes the timedevelopment of the drying shrinkage $\varepsilon_{c d s}\left(t, t_{s}\right)$ and is given as (with an additional proposed correction parameter $\alpha_{T}$ ):

$$
\beta_{d s}\left(t, t_{s}\right)=\frac{t-t_{s}}{\left(t-t_{s}\right)+0.04 \sqrt{\left(\alpha_{T} h_{0}\right)^{3}}}
$$

where $h_{0}=2 A_{c} / u ; A_{c}$ is the cross-section and $u$ is the perimeter of the member in contact with the atmosphere.; $\alpha_{T}$ is a proposed shape correction factor for T-beams. Some examples for $h_{0}$ are shown in Table 1 . 
Table 1. Expected value for notional size $h_{0}$ according to Eurocode 2 applied to a square, circle and T-beam.

\begin{tabular}{|c|c|c|}
\hline $\begin{array}{c}\text { Shape geometry of cross- } \\
\text { section }\end{array}$ & Shape description & $h_{0}=\frac{2 A_{c}}{u}($ EN1992-1-1) \\
\hline & \multirow[b]{2}{*}{ Square } & $Z$ \\
\hline $\mathrm{z}$ & & $\overline{2}$ \\
\hline $\mathrm{D}$ & \multirow{2}{*}{ Circle } & $\underline{D}$ \\
\hline & & $\overline{2}$ \\
\hline $\mathrm{a} \square^{\mathrm{z}} \square \uparrow_{\mathrm{z}}$ & \multirow{2}{*}{ T-beam (see figure 1) } & $2 a z-a^{2}$ \\
\hline\lfloor & & $2 z$ \\
\hline
\end{tabular}

The parameter $\alpha_{T} h_{0}$ was determined based on the equation for $\beta_{d s}\left(t, t_{s}\right)$ using a least squares approximation of the drying shrinkage behaviour obtained by the numerical simulations. A comparison of the estimated notional size with correction factor $\alpha_{T} h_{0}$ obtained from simulations and the notional size parameter $h_{0}$ as defined by Eurocode $2\left(h_{0}=2 A_{c} / u\right)$ is shown in Table 2 and Figure 5.

Table 2. Comparison of estimated values for notional size $h_{0}$ with the expected value according to Eurocode 2.

\begin{tabular}{lrrrlrrr}
\hline & $\alpha_{T} h_{0}$ & $h_{0}$ & $\alpha_{T}$ & & $\alpha_{T} h_{0}$ & $h_{0}$ & $\alpha_{T}$ \\
\hline R200 & 76.8 & 100 & 0.77 & T400A200 & 120.9 & 150.0 & 0.81 \\
R250 & 100.0 & 125 & 0.80 & T400A250 & 152.2 & 171.9 & 0.89 \\
R300 & 125.1 & 150 & 0.83 & T400A300 & 165.2 & 187.5 & 0.88 \\
R350 & 152.1 & 175 & 0.87 & T400A350 & 181.1 & 196.9 & 0.92 \\
R400 & 181.0 & 200 & 0.90 & T500A50 & 25.1 & 47.5 & 0.53 \\
R450 & 211.7 & 225 & 0.94 & T500A100 & 53.7 & 90.0 & 0.60 \\
R500 & 244.3 & 250 & 0.98 & T500A150 & 86.5 & 127.5 & 0.68 \\
C200 & 82.5 & 100 & 0.82 & T500A200 & 122.7 & 160.0 & 0.77 \\
C250 & 97.8 & 125 & 0.78 & T500A250 & 160.5 & 187.5 & 0.86 \\
C300 & 121.4 & 150 & 0.81 & T500A300 & 184.4 & 210.0 & 0.88 \\
C350 & 144.9 & 175 & 0.83 & T500A350 & 223.9 & 227.5 & 0.98 \\
C400 & 170.8 & 200 & 0.85 & T500A400 & 240.1 & 240.0 & 1.00 \\
C450 & 199.3 & 225 & 0.89 & T500A450 & 245.0 & 247.5 & 0.99 \\
C500 & 231.2 & 250 & 0.92 & T800A800 & 478.6 & 400.0 & 1.20 \\
T300A50 & 25.3 & 45.8 & 0.55 & T800A600 & 455.9 & 375.0 & 1.22 \\
T300A100 & 53.8 & 83.3 & 0.65 & T800A400 & 303.5 & 300.0 & 1.01 \\
T300A150 & 76.2 & 112.5 & 0.68 & T800A200 & 123.7 & 175.0 & 0.71 \\
T300A200 & 111.8 & 133.3 & 0.84 & T1000A1000 & 661.7 & 500.0 & 1.32 \\
T300A250 & 124.4 & 145.8 & 0.85 & T1000A800 & 649.8 & 480.0 & 1.35 \\
T400A50 & 25.2 & 46.9 & 0.54 & T1000A600 & 521.5 & 420.0 & 1.24 \\
T400A100 & 53.7 & 87.5 & 0.61 & T1000A400 & 309.6 & 320.0 & 0.97 \\
T400A150 & 86.3 & 121.9 & 0.71 & T1000A200 & 124.3 & 180.0 & 0.69 \\
\hline
\end{tabular}




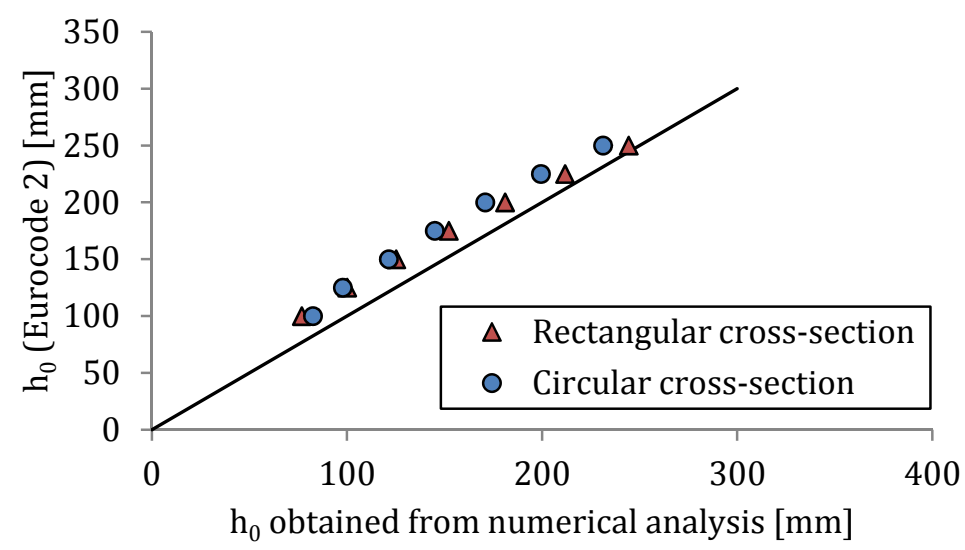

Figure 5. Comparison $\alpha_{\mathrm{T}} \mathbf{h}_{0}$ obtained by simulations and $\mathbf{h}_{0}$ according to Eurocode 2 for rectangular and circular cross-sections.

The goal of this paper is to define a general parameter $\alpha_{T}$ to denote the influence of the shape and size of T-beams on the drying shrinkage development. The following equation is proposed (with $\mathrm{R}^{2}$ equal to 0.93 ):

$$
\alpha_{T}=1.3 \cdot a^{0.33}
$$

in which $\alpha_{T}$ is the shape correction factor for T-beams and $a$ is the thickness of the flange in meters (see Figure 1). A comparison of the proposed correction factor $\alpha_{T}$ given by the proposed equation and the value of $\alpha_{T}$ obtained by numerical results is shown in Figure 6.

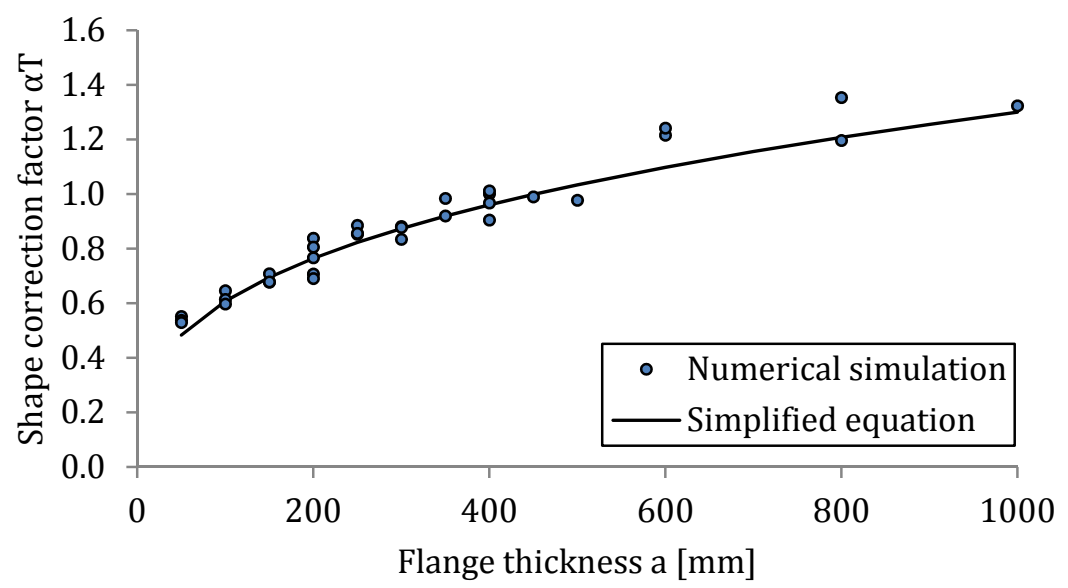

Figure 6. Comparison proposed equation for $\alpha_{T} h_{0}$ and numerical results.

\section{CONCLUSION}

- The time-development of the drying shrinkage behaviour obtained by the numerical analysis for prisms and cylinders is comparable with the function $\beta_{d s}\left(t, t_{s}\right)$ given by EN 1992-1-1 based on the notional size $h_{0}$. 
- The presented results are based on simplifications and give agreeable results even in the case in which the effect of creep is neglected. Further refinements can be included to enhance the modelling of drying shrinkage.

- There is a large influence of the geometry of T-shaped beams on the drying shrinkage behaviour caused by the different flow paths for moisture transport and a simple modification parameter $\alpha_{T}$ was proposed in order to account for this effect.

\section{REFERENCES}

ACI 209R. (1998). Prediction of creep, shrinkage, and temperature effects in concrete structures. Amer concr inst Detroit.

Bazant, Z. P., \& Baweja, S. (1995). Justification and refinement of Model B3 for concrete creep and shrinkage. 1. Statistics and sensitivity. Materials and structures, Vol.28.

Bazant, Z. P., \& Najjar, L. J. (1972). Nonlinear water diffusion In nonsaturated concrete. Materiaux et Constructions, Vol.5(No.25).

Bazant, Z. P., \& Xi, Y. (1994). Drying creep of concrete: constitutive model and new experiments separating its mechanisms. Materials and structures, Vol.27, pp.3-14.

Fib. (2010). CEB-FIP Model Code 2010 In Comite Euro-Int Du Beton (Ed.), Design code.

Ghali, A., Favre, R., \& Elbadry, M. (2011). Concrete Structures: Stresses and Deformations: Analysis and Design for Sustainability (4th edition): CRC Press.

Jefferson, A. D., \& Lyons, P. (2010). Comparison of approaches for simulating moisture content changes in concrete. Paper presented at the EURO-C 2010.

Kim, J. K., \& An, G. H. (2012). An Analytical Study of Long-term Deformation in SRC Columns Considering Differential Moisture Distribution. Paper presented at the Proceedings of the 3rd JCI-KCI-TCI Symposium on Recent Advancement of Technologies in Concrete Engineering Japan Concrete Institute.

Reybrouck, N., Maes, M., Caspeele, R., Criel, P., \& Taerwe, L. (2014). Modeling the effect of random environmental influences on stochastic creep in concrete members. Paper presented at the 12th international probabilistic workshop.

RILEM. (2015). Model B4 for creep, drying shrinkage and autogenous shrinkage of normal and high-strength concretes with multi-decade applicability. In TC242-MDC (Ed.), (Vol. Vol.48). Materials and Structures.

Seol, H. C., Kwon, S.-H., Yang, J.-K., Kim, H.-S., \& Kim, J.-K. (2008). Effect of differential moisture distribution on the shortening of steel-reinforced concrete columns. Paper presented at the Magazine of Concrete Research.

Su-Tae, K., Jeong-Su, K., Yun, L., Yon-Dong, P., \& Jin-Keun, K. (2011). Moisture Diffusivity of Early Age Concrete Considering Temperature and Porosity. KSCE Journal of Civil Engineering. 